\title{
Perfiles
}

JAIME RIVAS

\section{Pedro Geoffroy Rivas, la mágica raíz olvidada}

Algunos habrán consultado, en la escuela, el "Lexicon" de La lengua salvadoreña; habrán reído y rememorado glosas desaparecidas, familiares, quizás, sólo para los abuelos o bisabuelos. Otros, probablemente, habrán tenido entre manos alguna composición poética, deleitándose con el canto mítico Los nietos del jaguar o con los Cuadernos del exilio. Finalmente, habrá quienes hayan "devorado" la novela de Roque Dalton, Pobrecito Poeta que era $y o$, y recordado la relación que un día unió a este poeta rebelde y a los otros escritores de la llamada Generación Comprometida con un indiscutible maestro de generaciones: Pedro Geoffroy Rivas.
Pero aquéllos -los lectores asiduos de Geoffroy Rivas-son los menos - como gustaba decir a Nietzsche respecto de los lectores que deseaba-. El antropólogo, lingüista, ensayista, poeta y periodista, fallecía en la ciudad de San Salvador el 10 de noviembre de 1979. Su deceso pasó casi inadvertido en la prensa de la época - únicamente $L a$ Prensa Gráfica, dos días después, reseñaba parcamente su muerte, apuntando que ésta "ha sido muy sentida en los círculos intelectuales y populares del país”- En los veinticinco años que nos separan de su desaparición física, salvo algunos valiosos trabajos, tampoco se ha hecho mucho por preservar 
y transmitir la obra del insigne poeta. Mucho menos por continuarla sistemáticamente, a partir de investigaciones en el campo antropológico o lingüístico, por ejemplo. Ni siquiera, a propósito de los cinco lustros que nos separan de su muerte, se organizaron eventos oficiales, recitales o memoriales públicos. La vida $y$ obra de Geoffroy Rivas parece ser - parafraseando el título que el poeta Luis Alvarenga diera a una antología de ensayos suyos- la "mágica raíz", pero olvidada.

\section{Vida de un poeta, vida de un país}

La vida y obra de Pedro Geoffroy Rivas coincide con una de las etapas más intensas de la historia salvadoreña, pero, aún así, ha pasado casi desapercibida como producto de la amnesia colectiva, en un país cuyos habitantes tienen escasa memoria histórica. En estos veinticinco años, la obra del santaneco ha sido eclipsada, en primer lugar, en el marco del oscurantismo de la guerra $y$, en segundo término, por la desidia de una cultura que olvida fácilmente, que vive del momento, por no mencionar el insuficiente esfuerzo estatal por recuperar del olvido figuras de la talla de nuestro poeta.

La guerra y la posguerra son, pues, los referentes históricos más próximos a nosotros. Pero con Goeffroy Rivas se puede bucear por las profundidades de la historia salvadoreña reciente, coincidiendo con buena parte del siglo XX. Nacido en Santa Ana, el 16 de septiembre de 1908, ha sido parte activa de El Salvador del último siglo, pese a sus prolongados exilios.

Proveniente de una familia de hacendados - su padre fue el terrateniente francés Pierre Geoffroy Dubois, afincado en Santa Ana-, el poeta se aparta del camino que seguramente le tenía trazado su casa paterna, para abrazar los ideales revolucionarios. "Revoltoso, desacralizador y vanguardista, perseguido y exiliado numerosas veces $[\ldots]$ fue por su poesía y su actitud vital que llegó a convertirse en una especie de héroe cultural para muchos escritores". Su vida, concluye Miguel Huezo Mixco, puede ser definida como una "metamorfosis".

Los biógrafos del poeta son escasos. Rafael Lara Martínez, quien más se ha dedicado a difundir la obra de Geoffroy Rivas dentro y fuera del país, apunta en su nota biográfica que "su primera publicación data de noviembre de 1928 , en el Diario de Santa Ana, de su ciudad natal. Se inició como poeta que canta el amor; esta vena la seguirá explorando hasta su ma

\section{8}

Realidad 103, 2005 
durez con la publicación de un poemario antológico, Sólo amor (1963). Participó en la revista del Grupo Literario Crisol (1933) prosigue Lara Martínez- en su misma ciudad natal. Ahí colaboró con el reconocido filósofo Julio Fausto Fernández".

La vida de Geoffroy Rivas estuvo ligada estrechamente a dos de los episodios más importantes de la historia salvadoreña reciente. El primero de ellos, la masacre de 1932 en el occidente del país. Años antes se había trasladado a San Salvador para iniciar los estudios de medicina en la Universidad de El Salvador, donde se encuentra con Alfonso Luna, antiguo compañero suyo que lo vincula con Mario Zapata y Farabundo Martí, líderes comunistas de la época. Suspende sus estudios y se marcha a Guatemala y México, país donde se reencuentra con la vida universitaria y más tarde se relaciona con las doctrinas socialistas. Allí mismo estudiará antropología y lingüística, obteniendo una conciencia indigenista.

Regresa en 1931 a El Salvador y "reanuda sus nexos con Luna - escribe Luis Alvarenga- y la policía comienza a seguirle los pasos". Se marcha a México nuevamente, justo antes de aquel triste enero de 1932. Desde tierras az- tecas, junto con Gilberto González y Contreras, Geoffroy Rivas es el primero en denunciar el etnocidio de Izalco y sus alrededores. La sensibilidad y denuncia política le empiezan a caracterizar. Se afilia al Partido Comunista Mexicano.

Retorna nuevamente a El Salvador en 1944, cuando caía el General maximiliano Hernández Martínez — segundo episodio coincidente con la vida de Geoffroy Rivas-. Antes había estado preso en México, por protestar en ese país en contra de la política exterior de Martínez: "cuando Martínez reconoció a Franco como gobierno de España, nosotros fuimos a protestar a la Embajada de El Salvador en México - recoge Luis Alvarenga de una entrevista realizada a Geoffroy Rivas y publicada en $E l$ Universal, en 1979-. La protesta consistió en echarle un galón de gasolina al edificio y pegarle fuego. Nos agarró la policía y se armó un escándalo tremendo [...] Eso fue el año 36, yo iba terminando la carrera y me sirvió de mucho estar encerrado todo ese tiempo, porque estudié bastante y pude doctorarme. Allí a la penitenciaría -concluye Geoffroy Rivas - llegaron a examinarme y también allí me imprimieron mi tesis". 
Defenestrado Martínez, se ocupó de la dirección del periódico La Tribuna, desde donde proyectó una conciencia cívica contraria a los intereses promartinistas, lo cual le valió un nuevo exilio, obligado por los sucesivos regímenes de Osmín Aguirre y Salvador Castaneda Castro. El segundo exilio duró hasta 1957, cuando retornó al país. Hacia esa fecha, cuentan sus biógrafos, ya era un icono para las nuevas generaciones de poetas, especialmente para la Generación Comprometida, entre quienes se cuentan Manlio Argueta y Roque Dalton. Este último retoma un verso de Rivas para titular un libro suyo: Pobrecito poeta que era $y o$, aunque después no le perdonará su distanciamiento y críticas al Partido Comunista Salvadoreño (PCS). Como quiera que sea, Geoffroy Rivas se había convertido en un paradigma vital y moral.

"Debido a sus capacidades intelectuales y a su prestigio académico - apunta Carlos CañasDinarte-, pronto fue designado catedrático de sus especialidades en el Alma Mater nacional y director del Museo Nacional ' $\mathrm{Da}$ vid J. Guzmán'. Atrapado entre quienes le cerraban espacios al tildarle de comunista y los que le criticaban por su distanciamiento del PCS, Geoffroy Rivas se fue vinculando, con dificultades, a la vida institucional del país. Publicó en importantes revistas como La Universidad, ECA y Cultura. Sólo en esta última publicación se recogen 12 intervenciones suyas desde 1958. En 1966 es recibido en la Academia Salvadoreña de la Lengua, en cuya ceremonia de recepción pronuncia un impresionante discurso titulado "Pero los nietos del jaguar aún estamos aquí", donde confiesa sus opciones vitales - actitud escasa hoy en día- y recrea el peregrinar de los pueblos nahuas que se asentaron en el actual territorio salvadoreño.

Escribe y publica sobre antropología, lingüística e historia, representando un notable avance en su época, pese a las deficiencias que se aprecian hoy en día. Se ocupó también de la poética indigenista: "quizás su mayor contribución -concluye Rafael Lara Martínez- sea rescatar temas indigenistas, en una sociedad que ha rechazado tanto cualquier lazo cultural con lo prehispánico, así como con las minorías étnicas nacionales". En 1977, el gobierno salvadoreño le concede el "Premio Nacional de Cultura". La muerte le sorprende dos años más tarde, un sábado 10 de noviembre, mientras se gestaba el conflicto 
armado que explotaría al año siguiente.

\section{La rebeldía no debe conducir al olvido}

Geoffroy Rivas se confiesa poco gregario, susceptible de formar masas, ni le gusta la pompa. Cuando el 25 de marzo de 1966 fue llamado para investirlo como miembro de la Academia Salvadoreña de la Lengua se define como "enemigo inveterado de toda agregación, anarquizante contumaz - como todo poeta- he huido siempre de los cónclaves, de los arrebañamientos, ya sean culturales, políticos o de cualquier otra índole. Las poquísimas veces -que no llegan a tres- en que he aceptado agruparme, me he distinguido como elemento disociador, como prototipo de la indisciplina, promotor del desorden, abanderado de la rebelión".

Ese talante rebelde se pone de manifiesto también en el estudio que antecede al "Lexicon" de $\mathrm{La}$ lengua salvadoreña. Allí, Geoffroy Rivas apunta que "el purismo constituye en realidad una falta científica contra la lengua. Ante todo porque es esencialmente antievolucionista. Nuestros puristas sueñan con inmovilizar la lengua. Cuando evocan su buen uso, nos remiten generalmente a Cervantes, como si nada hubiese sucedido en el ámbito del idioma español en los cuatrocientos años que nos separan del Quijote”.

Ahora bien, ese talante rebelde, casi anárquico — podrían alegar quienes justifican el olvido que ha sufrido la obra de nuestro autor- habría alimentado el silencio oficial respecto de la vida y obra de Geoffroy Rivas. No sólo se trata de reprochar el olvido de los 25 años de su muerte -un recuerdo que hubiera sido propicio para volver sobre su obra, como en el 2005 se hace de Hugo Lindo-. Se trata de replantearse entre la comunidad de académicos, poetas, investigadores, antropólogos, lingüistas e historiadores lo que se ha hecho hasta la fecha en los diversos campos en los que incursionó el poeta.

Actualmente, pocos defienden con ahínco y profesionalidad, por poner un ejemplo incómodo, la causa indigenista y la búsqueda de las identidades salvadoreñas a partir de esa herencia irrenunciable de nuestro mestizaje como lo es la herencia natural y cultural indígena. Quienes investigan sobre la identidad soslayan que la misma empezó a forjarse, aunque sea involuntariamente, por los pueblos que habitaron la comarca, esos "pueblos de un empuje vital no superado hasta ahora por ningún otro pueblo de la Tierra. Pue- 
blos imagineros, de alto pensamiento mágico, que recorrieron la mitad del Continente, a lo largo y a lo ancho, poblando de sueños el ambiente, transformando en vívido misterio el cotidiano acontecer".

El excusable olvido de la obra de Geoffroy Rivas es el imperdonable olvido de la herencia indígena salvadoreña y, peor aún, de la marginación sistemática de las minorías étnicas nacionales.

"¿He de marcharme entonces? ¿Sólo un instante viviré sobre el mundo?
iOh, amigos!

No dejéis que perezca del todo". Conservad este canto".

$\mathrm{El}$ anterior es un verso suyo, retomado de un poemario y destacado también por Luis Alvarenga al introducir la antología La mágica raíz. Es bastante probable que Pedro Geoffroy Rivas haya rehuido cualquier homenaje - como el que modestamente se quiere hacer aquí-, pero sí estuviera totalmente a favor de que las generaciones posteriores continuaran indagando, con entrega, sobre nuestros orígenes. 